\title{
Effects of Video Game Playing on the Circadian Typology and Mental Health of Young Czech and Japanese Children
}

\author{
Milada Krejci ${ }^{1}$, Kai Wada ${ }^{1,2}$, Miyo Nakade ${ }^{3}$, Hitomi Takeuchi ${ }^{3}$, Teruki Noji ${ }^{4}$, Tetsuo Harada ${ }^{2}$ \\ ${ }^{1}$ Department of Health Education, Faculty of Education, University of South Bohemia, \\ Jeronymova, Ceske Budejovice, Czech Republic; \\ ${ }^{2}$ Laboratory of Environmental Physiology, Graduate School of Integrated Sciences of Human and Nature, \\ Kochi University, Akebonocho, Kochi, Japan; \\ ${ }^{3}$ Department of Foods and Nutrition, Tokai-Gakuen University, Nagoya, Aichi, Japan; \\ ${ }^{4}$ Department of Physical Education, Faculty of Education, Kochi University, Kochi, Japan. \\ Email: haratets@kochi-u.ac.jp \\ Received May $9^{\text {th }}, 2011$; revised July $27^{\text {th }}, 2011$; accepted September $2^{\text {nd }}, 2011$.
}

\begin{abstract}
The objective of this study is to examine the effects of video game playing on sleep-wake cycles and mental health of young Czech and Japan children. A cross-sectional survey with 497 Czech children (240 girls, 257 boys; mean age of 4.60 years; $49^{\circ}-51^{\circ} \mathrm{N}$ ) and 599 Japanese children ( 314 girls, 285 boys: 3.79 years; $33^{\circ} \mathrm{N}$ ) from 20 kindergartens and nursery schools. $20 \%$ and $30 \%$ of Czech and Japanese children had their own video game devices. Young children who played video games every day had later sleep and wake times $(P<0.001)$ and were more evening-typed $(P<0.001)$ than those who did not every day in the both countries. The longer Czech children played video games per time, the later sleep and wake times were $(P<0.001)$. Czech children who played video games from 18:00 - 21:00 showed later sleep times and shorter sleep hours $(P<0.001)$ on weekdays than those who played at earlier times. Japanese children who played video games from 18:00 - 21:00 were more evening-typed and woke up later than those who played at earlier times $(P<0.001)$. Czech children who had their own video game devices had a higher frequency of anger than those who did not $(P<0.001)$. Habitual video game playing in the evening may make children more evening-typed and it may also be speculated to make them more aggressive in both countries.
\end{abstract}

Keywords: Chronotype, Video Game Playing, Circadian Typology, Mental Health

\section{Introduction}

Issues concerning diurnal rhythms and sleep health are important to health professionals, school teachers, parents and the children themselves. Video games have become one of the major playing tools for children all over the world. Many epidemiological studies have been done on the relationship of video game playing with sleep health and physical health of primary and secondary school children, mainly aged $6-15$ yrs.

Video-game use more than $1 \mathrm{~h}$ by $6-12$ yrs and more than 2 $\mathrm{h}$ by junior high students were reported to promote black rings under the eyes (BR) and muscle stiffness in the shoulder (MS) (Tazawa \& Okada, 2001) and longer sleep onset latency (Kagamimori, 2006), respectively. In Singapore, a questionnaire study on children aged $6-12$ yrs showed that total sleep time (TST) was reduced by playing computer games after 20:00 (BaHammam et al., 2006). An epidemiological study on German primary school children revealed that $11 \%$ of them played computer games more than 3 hours daily and went to bed after 21:00 (Gaina et al., 2007), and another study on German children aged 5 - 11 yrs showed that viewing TV or playing video games before sleep was associated with sleep and behavior problems (Wiater et al., 2008). A questionnaire study on Belgium adolescents showed that those who played more time computer games went to bed later and woke up later (Van Den Bulck, 2004). A postal inquiry study on Finns aged 12 - 18 yrs substantiated the mediating hypothesis that intensive ICT (Information Communication Technology) was associated with poor sleep health and increased waking-time tiredness (Punamaki et al., 2007). Yokomaku et al. (2008) reported that eve- ning-typed infants aged $4-6$ yrs showed more several problematic behaviors than non-evening-typed ones.

Some experimental interference studies have been done so far on the effects of computer game playing. Playing the game prolonged sleep latency in Japanese adult males (Higuchi et al., 2005). Dworak et al. (2007) reported that playing game reduced slow-wave-sleep, declined verbal memory performance, prolonged sleep-onset latency and increased stage 2 sleep on school-aged German children. Smyth (2007) also reported that the TV game playing decreased sleep quality in $18-20$ yrs olds students. However no experimental studies have been done on video game effects upon the aspects of mental health. Light exposure from a fluorescent lamp promotes an evening-type life-style, and elementary school students were more sensitive to light than University students (Harada \& Takeuchi, 2001; Harada, 2008). Light emitting from a computer game display is predicted to delay the circadian phase of young children which may be more sensitive to light rather than elementary school students.

Exposure to strong blue lights from the displays of video game devices during the first half of subjective night may depress the plasma melatonin level of Japanese junior high school students (Harada, 2004) as well as cause a delay in the phase of the human circadian clock (Honma \& Honma, 1988). According to an epidemiological study on 5th grade students aged 10 - 11 yrs attending elementary schools all over the Japan, $92 \%$ of such students had their own video game device in 2007 (Japan Parents and Teachers Association, 2007). Playing video games occupies a great amount of free time and psychological space in children. Video game playing has been hypothesized to 
reduce the blood flow and disturb electro-physiological activeties in the frontal lobe of the cerebral cortex (Mori, 2002). Lights emitted from the displays of video games may stimulate the SCN (suprachiasmatic nucleus) which is thought to be the controlling center of the circadian system Herman (Herman, 2008).

However, there have been no integrated studies conducted on the effects of video game playing on circadian typology, sleep habits and mental health of children aged $2-6$ yrs when the fundamental physiological systems governed by the circadian clock systems are developing. In this study, the effects of video game playing on the young children are hypothesized to be much higher than the effects on high school and University students. This might be because the daytime serotonin level in the brain and nighttime plasma melatonin level are much higher in 3 - 8 year olds than in older children, and the amount of suppression of plasma melatonin promoted by light from fluorescent lamp is also expected to be higher in younger children (Harada, 2004; Waldhauser et al., 1988).

This study aims at examining the effects of video game playing on sleep-wake cycles based on circadian typology and mental health of children aged 2 - 6 years living in "morningtyped" (Czech) and "evening-typed" (Japan) societies (Wada et al., 2009) from an epidemiological point of view.

\section{Participants and Methods}

\section{Study Site}

The study was conducted in 20 public kindergartens and nursery schools, distributed all over the Czech Republic $\left(49^{\circ}-\right.$ $51^{\circ} \mathrm{N}$ ) (mainly South-Bohemia region) located in central Europe, and distributed in Kochi City $\left(33^{\circ} \mathrm{N}\right)$ in Kochi Prefecture facing the Pacific Ocean in the southern half of Shikoku Island in Japan. The Czech Republic and Japan are typical "morning-typed" and "evening-typed" societies, respectively. For example, the first class in the morning at Czech and Japanese Universities starts at 8:00 and 8:50, respectively. Similarly, Czech and Japanese kindergartens start at 6:30 - 8:00 and 8:30 $9: 30$, respectively. Most official bus and train services start at 4:00 - 5:00 in the Czech Republic and 5:00 - 6:00 in Japan. Czech laborers in factories start work at 6:00 in the Czech Republic, whereas Japanese laborers start at 8:00 - 9:00. Many Czech and Japanese official services open at 7:30 - 8:00 and 9:00, respectively. On the other hand, Czech labors stop to work earlier than Japanese ones. The official working hours of public employees per day is legislated to be 8.5 hours in Czech and 8 hours in Japan (Czech: 8:00 - 17:00 or 7:30 - 16:30, Japan: 8:30 - 17:30 including 0.5 h (Czech) and $1 \mathrm{~h}$ (Japan) of lunch break in many cases). Young Czech children are expected to use video games in earlier hours of the evening than young Japanese children. As a result, smaller effects of using video games can be expected in young Czech children than in young Japanese children.

\section{Participants}

As kindergarten staffs have more free-time to be spent for the management of the questionnaire work in the spring than in the fall in the Czech Republic and vice versa in Japan, participation in fall was recommended by kindergartens in the Czech Republic and in spring for Japan. Among randomly selected children attending one of 11 kindergartens (for children aged 2 - 6), 497 children (response rate: $86 \%$; 240 girls, 257 boys; $2 \mathrm{y}: 15 ; 3 \mathrm{y}$ :
77; 4y: 110; 5y: 184; 6y: 111; mean \pm SD: $4.60 \pm 1.09 y)$ participated in this study from the Czech Republic. Japanese 599 children among those for whom we asked to answer the questionnaire, participated in (response rate: $70 \% ; 314$ girls, 285 boys: $2 \mathrm{y}: 100,3 \mathrm{y}: 153,4 \mathrm{y}: 149,5 \mathrm{y}: 165,6 \mathrm{y}: 32$; mean \pm SD: $3.79 \pm 1.17 \mathrm{y}$ ). The participants attended one of 1 kindergarten (for children aged $4-6$ ) and 9 nursery schools (for babies and children aged 0 - 6) governed by Kochi City in Kochi Prefecture of Japan $\left(33^{\circ} \mathrm{N}\right)$. These 9 nursery schools were also randomly selected from all 25 nursery schools governed by Kochi city. Babies and young children aged 0 - 1 were excluded from the study because of flexible sleep-wake cycles.

\section{Questionnaire}

To measure diurnal preference of the young children, a Japanese and Czech version for children (Harada et al., 2007) of MEQ originally constructed by Torsvall and Åkerstedt (1980) was administrated. This MEQ consisted of seven questions: three pertaining to sleep offset timing in the morning, one to the peak timing of activity during the daytime and three to sleep onset timing in the evening, which of young children was judged due to the observation in holidays by mostly their mothers $(>95 \%)$. Answer can be selected from 4 alternatives in each question, and the total of 7 answers can range from 7 (extremely evening-typed) to 28 (extremely morning-typed).

Czech and Japanese versions of an integrated questionnaire (34 questions for children and 11 questions for their parents) which consisted of a morningness-eveningness (M-E) questionnaire (MEQ) originally constructed by Torsvall and Åkerstedt (1980) and an original questionnaire on sleep habits (Harada et al., 1988), video game playing and mental health and were completed in June or November 2007 to avoid the severe summer and winter seasons.

A Japanese version of the integrated questionnaire has been used in several studies (Harada, 2008; Harada et al., 2007; Harada et al., 2006). An English version (Harada et al., 1998) of a questionnaire which includes most of the integrated questionnaire was translated to Czech by Krejci (author). The English version of a questionnaire about video games that Harada (author) constructed was translated to Czech and Japanese by Krejci and Harada. Lastly, a detailed discussion, check and revision were made by four academic members (including one author: Krejci) of the Department of Health Education, Faculty of Education, University of South Bohemia, and two Japanese authors (Harada and Wada) on the integrated questionnaire to ensure that both translations were as similar as possible.

\section{Statistical Analysis of Questionnaire Data}

The questionnaire was distributed to all or some of the children attending randomly selected kindergartens or nursery schools. Parents ( $95 \%$ or more of which were mothers) answered the questionnaire for themselves (MEQ: 7 items, playing video games: 4 items) and also for their children (MEQ: 7 items, playing video games: 4 items, sleep habits: 11 items, meals: 8 items, mental health: 2 items, exposure to sunlight: 3 items). Fundamental comparisons on MEQ, sleep habits and mental health were performed between Czech and Japanese children (Table 1). Data was statistically analyzed with SPSS software (12.0 J for Windows; SPSS Inc., Chicago, IL, USA).

\section{Ethical Treatment}

The study followed the updated guidelines established by Chronobiology International for the conduct of research on 
Table 1 .

Comparison of circadian typology and sleep habits between Czech and Japanese children and their parents (mothers).

\begin{tabular}{|c|c|c|c|}
\hline & \multicolumn{3}{|c|}{ Mean \pm SD or $\%\left(\right.$ total $\left.\mathrm{N}^{\ddagger}\right)$} \\
\hline & Czech & Japan & $P$-value \\
\hline \multicolumn{4}{|c|}{ Circadian typology } \\
\hline \multicolumn{4}{|l|}{ ME scores } \\
\hline \multirow[t]{2}{*}{ Parents } & $9.6 \pm 3.3(604)$ & $20.0 \pm 3.2(682)$ & $0.025^{*}$ \\
\hline & (Median:20) & (20) & \\
\hline \multirow[t]{3}{*}{ Children } & $22.1 \pm 3.1(626)$ & $20.39 \pm 3.6(626)$ & $<0.001^{*}$ \\
\hline & (Median:22) & (20) & \\
\hline & \multicolumn{3}{|c|}{ Sleep habits of children } \\
\hline \multicolumn{4}{|l|}{ Bed time (h) } \\
\hline Weekday & $20.1 \pm 0.6(634)$ & $21.5 \pm 0.9(690)$ & $<0.001^{*}$ \\
\hline Weekend & $20.8 \pm 0.8(628)$ & $21.8 \pm 1.0(700)$ & $<0.001^{*}$ \\
\hline \multicolumn{4}{|l|}{ Wake up time (h) } \\
\hline Weekday & $6.7 \pm 0.3(630)$ & $7.0 \pm 0.6(702)$ & $<0.001^{*}$ \\
\hline Weekend & $7.4 \pm 0.8(628)$ & $7.5 \pm 0.9(698)$ & $<0.001^{*}$ \\
\hline \multicolumn{4}{|l|}{ Sleep latency (min) } \\
\hline Weekday & $17.1 \pm 10.7(634)$ & $21.0 \pm 14.1(701)$ & $<0.001^{*}$ \\
\hline Weekend & $15.2 \pm 11.0(624)$ & $18.7 \pm 13.9(698)$ & $<0.001^{*}$ \\
\hline \multicolumn{4}{|l|}{ Sleep hours } \\
\hline Weekday & $10.6 \pm 0.7(624)$ & $9.5 \pm 0.8(689)$ & $<0.001^{*}$ \\
\hline Weekend & $10.6 \pm 0.9(626)$ & $9.7 \pm 0.9(695)$ & $<0.001^{*}$ \\
\hline \multicolumn{4}{|c|}{ Difference between weekday and weekend in sleep habits of children } \\
\hline Bed time (h) & $0.7 \pm 0.6(622)$ & $0.3 \pm 0.8(688)$ & $<0.001^{*}$ \\
\hline Wake up time (h) & $0.7 \pm 0.7(628)$ & $0.5 \pm 0.7(697)$ & $0.033^{*}$ \\
\hline Sleep hours (h) & $-0.01 \pm 0.8(620)$ & $0.2 \pm 1.1(682)$ & $<0.001^{*}$ \\
\hline \multicolumn{4}{|c|}{ Mental health } \\
\hline \multicolumn{4}{|l|}{ \% Frequent "often" } \\
\hline Anger & 1.3 & $(633)$ & $9.3(678)^{\dagger}$ \\
\hline Depression & $12.6(626)$ & $0.7(676)$ & $<0.001^{\dagger}$ \\
\hline
\end{tabular}

Note: *Mann-Whitney U-test, ${ }^{\dagger} \chi^{2}$ test, ${ }^{\dagger}$ Totals vary as some respondents have not answered the questions. ${ }^{\#}$ after Wada et al.

human subjects (Portaluppi et al., 2010). The concepts and purpose of the study were carefully explained in writing and orally to kindergarten or nursery teachers and the parents of the children were told that questionnaires would be conducted in a completely unregistered manner and answers would be used only for academic purposes. After the explanation, all parents agreed to participate in the questionnaire study, which was administered at home.

\section{Results}

International comparisons in Table 1 include circadian typology, sleep habits and mental health. Czech children were more morning-typed and showed better sleep quality and quan- tity than Japanese children. However, there was larger phasedelay at bedtime in weekend in Czech children than in Japanese children. A larger number of Czech children than Japanese children felt "depressed", while the reverse was true for children who felt "anger".

$30.8 \%$ (females: 61 of $236,25.8 \%$; males: 90 of $254,35.4 \%$ ) and $27.1 \%$ (females: 74 of $306,24.2 \%$; males: 84 of 278 , $30.2 \%$ ) of Czech and Japanese children aged $2-6$ yrs played video games, ("players") respectively (Table 2). Players showed lower M-E scores (more evening-typed), later bedtime and wake-up time than non-players in Japanese children. In Czech children, players showed lower M-E scores (more evening-typed) than non-players. Few children aged $2-3$ yrs played video games, and $25.7 \%$ and $31.9 \%$ of 4 year old children played video games in the Czech Republic and Japan, respecttively (Table 2). Japanese children who played video games every day showed significantly lower MorningnessEveningness scores (more evening-typed) than those who did not play at all (Mann-Whitney U-test: $\mathrm{z}=-2.391, \mathrm{P}=0.017$ ) (Table 3(a)). Czech children who played video games every day tended to go to bed 30 minutes later than those who played 0 1 times per week (Table 3(a)). Czech children who played video games more than 0.5 hours per time showed significant later bed times than those who played $0-0.5$ hours (Table 3(b)) (Mann-Whitney U-test: $\mathrm{z}=-2.174, \mathrm{P}=0.030$ ). 79.2\% of Czech children who played video games did so from 15:00 to $18: 00$, whereas $63.4 \%$ of the Japanese children who played video games did so from 18:00 to 21:00. Both times of day correspond with sunset times of the study season. Czech children who played video games from 15:00 to 18:00 went to bed significantly later on weekdays than those who played at earlier times (Mann-Whitney U-test: $\mathrm{z}=-2.357, \mathrm{P}<0.018$ ) (Table 3(c)). Japanese children who played video games from 18:00 to 21:00 were significantly more evening-typed and woke up on average 20 minutes later in the morning than those who played at earlier times (Table 3(c)). The correlation value (r-value) between the morningness-eveningness (M-E) scores of children and mothers was relatively low $(\mathrm{r}=0.320)$ in Czech participants, whereas it was relatively high $(r=0.422)$ in Japanese participants.

Condition of mental health in Czech and Japanese infants was shown in Table 1. The higher the frequency of playing video games was per week, the lower the frequency of depresssion was only for Japanese children $\left(\chi^{2}\right.$-test, Czech: $\chi^{2}$-value $=$ 5.830, $\mathrm{df}=9, P=0.757$; Japan: $\chi^{2}$-value $=14.169, \mathrm{df}=6, P=$ $0.028)$. Instead, Japanese children who played video games tended to feel anger with significantly higher frequency than those who did not do so $\left(\chi^{2}\right.$-test, Czech: $\chi^{2}$-value $=6.190, \mathrm{df}=1$, $P=0.241$; Japan: $\chi^{2}$-value $\left.=6.120, \mathrm{df}=1, P=0.013\right)($ Figure 1$)$.

\section{Discussion}

Several factors could affect the circadian typology in adolescents and elder students: for example earlier sunrise leading to morning-typology (Randler, 2008: on adolescents); females with more advanced sleep phase than males (Tonetti et al., 2008: on 13 - 25 yrs students). Evening-typology could relate to lower mental health (Hirata et al., 2007: on 19 - 30 students; Harada, 2008: on 2 - 25 yrs) and higher scores of CBCL (Children Behavior Checklist $/ 4$ - 8 to detect several problematic behaviors) (Yokomaku, 2008: on 4 - 6 yrs children).

Habitual playing of video games might also affect the circadian typology of both Japanese and Czech young children 
Table 2 .

Fundamental data on video game playing by Czech and Japanese children aged 0 - 6 yrs in 2007.

\begin{tabular}{|c|c|c|c|c|c|c|c|c|c|c|c|c|c|c|}
\hline \multirow[t]{4}{*}{ Males } & \multicolumn{14}{|c|}{ Does your child use a video game device? } \\
\hline & \multicolumn{7}{|c|}{ Czech } & \multicolumn{7}{|c|}{ Japan } \\
\hline & \multicolumn{14}{|c|}{ Age } \\
\hline & 0 & 1 & 2 & 3 & 4 & 5 & 6 & 0 & 1 & 2 & 3 & 4 & 5 & 6 \\
\hline "Yes" & 0 & 0 & 1 & 4 & 15 & 40 & 30 & 0 & 0 & 4 & 7 & 29 & 34 & 10 \\
\hline$(\%)$ & $(0)$ & $(0)$ & (16.7) & (11.1) & $(28.3)$ & (41.7) & $(47.6)$ & $(0)$ & (0) & $(8.0)$ & (10.9) & (42.0) & $(42.5)$ & (66.7) \\
\hline "No" & 0 & 6 & 5 & 32 & 38 & 56 & 33 & 14 & 36 & 46 & 57 & 40 & 46 & 5 \\
\hline Total & 0 & 6 & 6 & 36 & 53 & 96 & 63 & 14 & 36 & 50 & 64 & 69 & 80 & 15 \\
\hline \multirow[t]{4}{*}{ Females } & \multicolumn{14}{|c|}{ Does your child use a video game device? } \\
\hline & \multicolumn{7}{|c|}{ Czech } & \multicolumn{7}{|c|}{ Japan } \\
\hline & \multicolumn{14}{|c|}{ Age } \\
\hline & 0 & 1 & 2 & 3 & 4 & 5 & 6 & 0 & 1 & 2 & 3 & 4 & 5 & 6 \\
\hline "Yes" & 0 & 0 & 0 & 4 & 13 & 27 & 17 & 0 & 0 & 6 & 13 & 17 & 30 & 8 \\
\hline$(\%)$ & $(0)$ & (0) & $(0)$ & $(10.3)$ & $(23.1)$ & (31.4) & $(37.0)$ & $(0)$ & (0) & (12.8) & (15.3) & $(22.7)$ & $(36.1)$ & $(50.0)$ \\
\hline "No" & 1 & 15 & 9 & 35 & 43 & 59 & 29 & 8 & 34 & 41 & 72 & 58 & 53 & 8 \\
\hline Total & 1 & 15 & 9 & 39 & 56 & 86 & 46 & 8 & 34 & 47 & 85 & 75 & 83 & 16 \\
\hline
\end{tabular}

(playing games leading to evening-type) and reduce sleep health like as the video game playing in the elder children (Kagamimori, 2006; BaHammam et al., 2006; Gaina et al., 2007; Wiater et al., 2008; Van Den Bulck, 2004; Punamaki, et al., 2007). This study shows that it is common for Japanese children to play video games in the evening from 18:00 to 21:00 which is around sunset and includes "dusk" in June in Kochi. Exposure to lights from the displays of video game devices, while playing video games in the evening could be hypothesized to have phase-delaying effects on the circadian clock. It is because the exposure to lights during 19:00 24:00 could cause a delay in the phase of children's circadian clocks (Honma \& Honma, 1988; Harada, 2004) and might reduce the plasma melatonin level as a "sleep onset agent" in the evening (Zhdanova et al., 1995; Harada, 2004). Japanese mothers could be more likely to synchronize their own diurnal rhythms to their children than Czech mothers. Strong discipline to prevent the use of video games after sunset might be critical, especially for Japanese children.

On the other hand, Czech children tended to play video games mainly from $15: 00$ to $18: 00$, which is earlier than the first half of subjective night, is around sunset and also includes "dusk" in November at Ceske Budejovice $\left(49^{\circ} \mathrm{N}\right)$. Playing video games around sunset may still cause a backward shift in both sleep and wake times, although it is much earlier than the first half of subjective night (around 18:00 24:00). Honma and Honma (1988) reported that exposure to bright lights from fluorescent lamps from 20:00 to 02:00 caused a delay in the phase of the circadian clock (which controls rhythms such as body temperature rhythms) of adult subjects. In the case of children, exposure to the lights from displays of video game devices even late in the afternoon might relate to the circadian clock phase and plasma melatonin level.

Positive associations between evening-type preference and depressive mood have been previously described in adults (Drennan et al., 1991; Chelminski et al., 1999) and adolescents (Giannotti and Cortesi, 2002; Takeuchi et al., 2002; Harada, 2008; Hirata et al., 2007). Several reports also have shown that de-synchronization of the circadian clock system and the social time schedule was often accompanied by a depressed mood (Harada, 2008). The current research showed that children aged 2 - 6 yrs in Japan also exhibited strong positive associations between evening-type preference and aggressive mental condition (anger and irritation) (Harada, 2008; Hirata et al., 2007). Playing video games in the evening or late afternoon might relate to higher levels of aggression as anger and irritation indirectly via the de-synchronization of the circadian clock or by directly affecting children's brains.

One limitation in this study that should be mentioned is that there was no investigation regarding the content of the video games. Recently, for example, Wei (2007) reported that playing violent video games on the Internet was associated with greater tolerance of violence, a lower empathetic attitude and more aggressive behavior in Chinese adolescents. A higher level of aggression shown by children who play video games in the evening or afternoon could be partially caused by more violent and frustrating content. Effects of video game content on mental health in children remain a question to be solved. Another shortcoming is the lack of correspondence in the sampling season. Spring data on the Czech Republic side and fall data on the Japanese side should be collected in the near future, although support from the nursery school staff would be hard to be obtained due to busyness in those seasons in the respective countries.

\section{Acknowledgements}

We would like to thank all the members of the kindergartens 
Table 3 .

(a) Relationship between frequency of playing video games, M-E scores and sleep habits (M: Mean, SD: Standard deviation) (number of children); (b) Relationship between duration of playing video games per once and M-E scores and sleep habits (M: Mean, SD: Standard deviation) (number of children); (c) Relationship between time of day to play video games and M-E scores and sleep habits (M: Mean, SD: Standard deviation) (number of children).

(a)

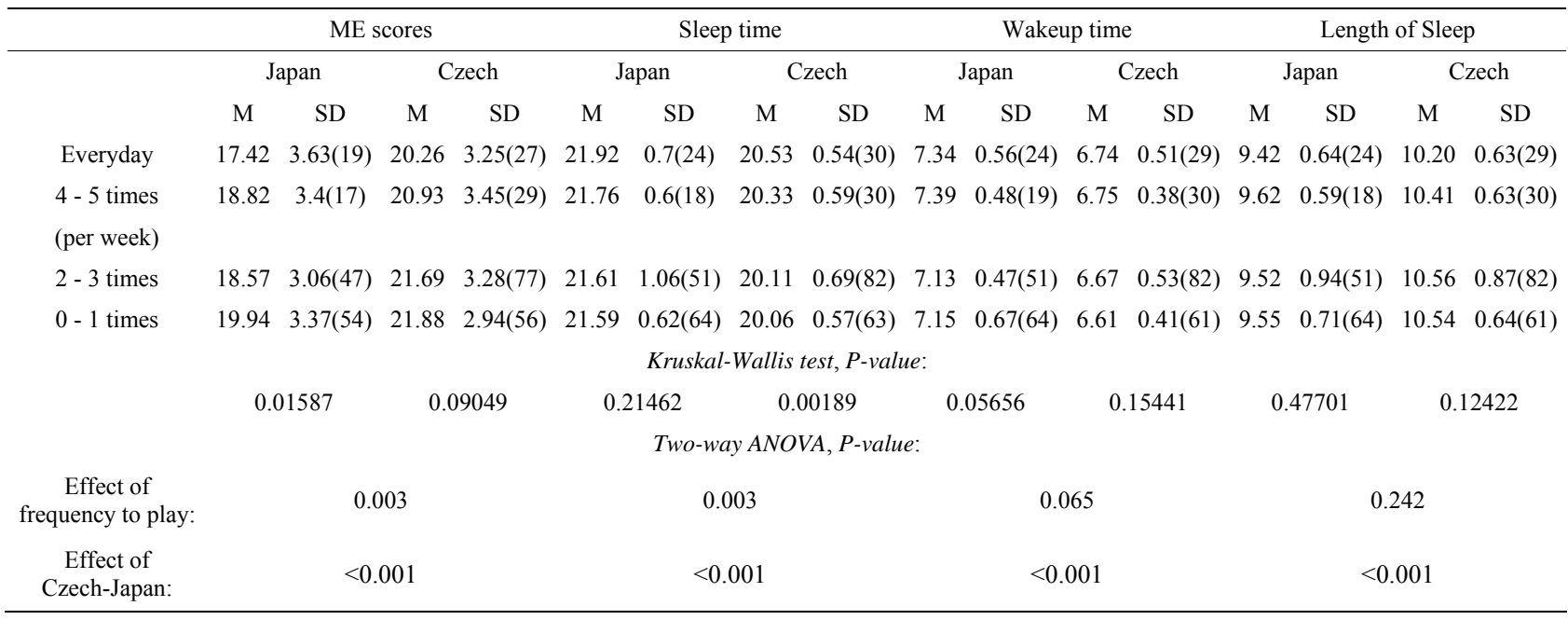

(b)

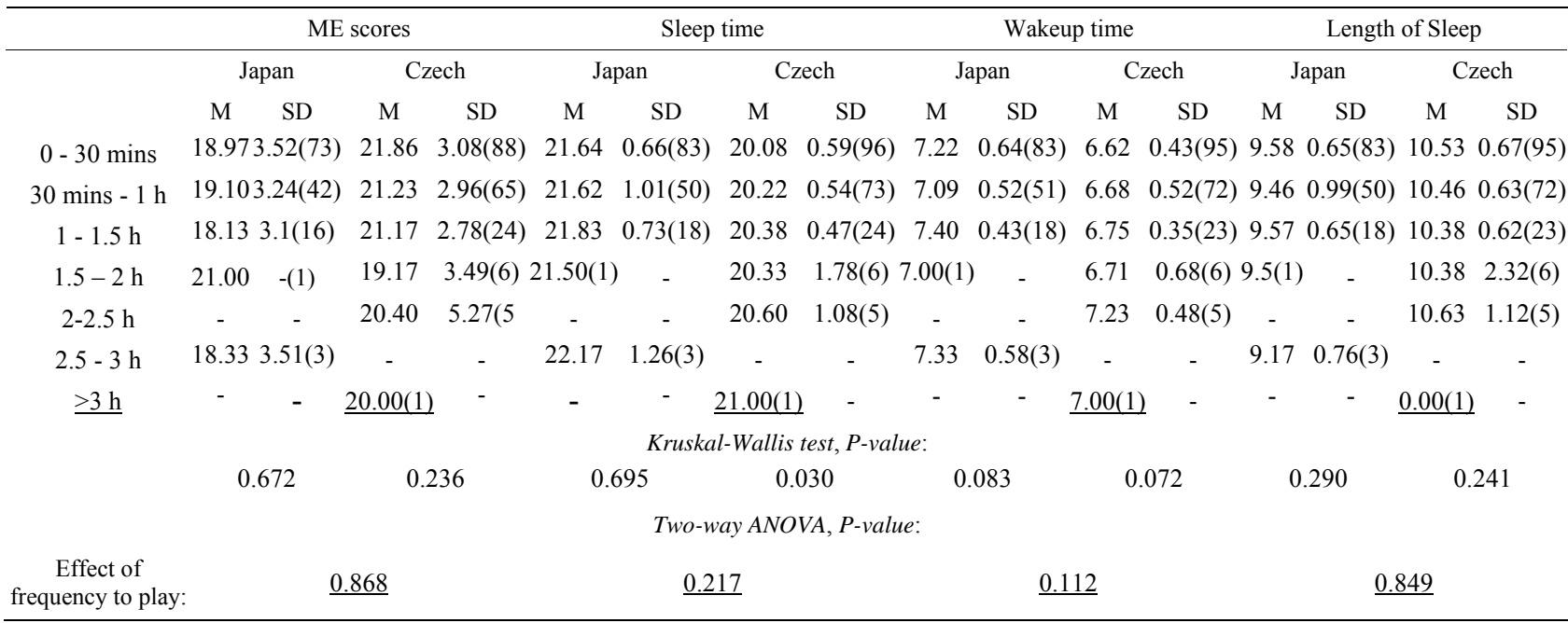

(c)

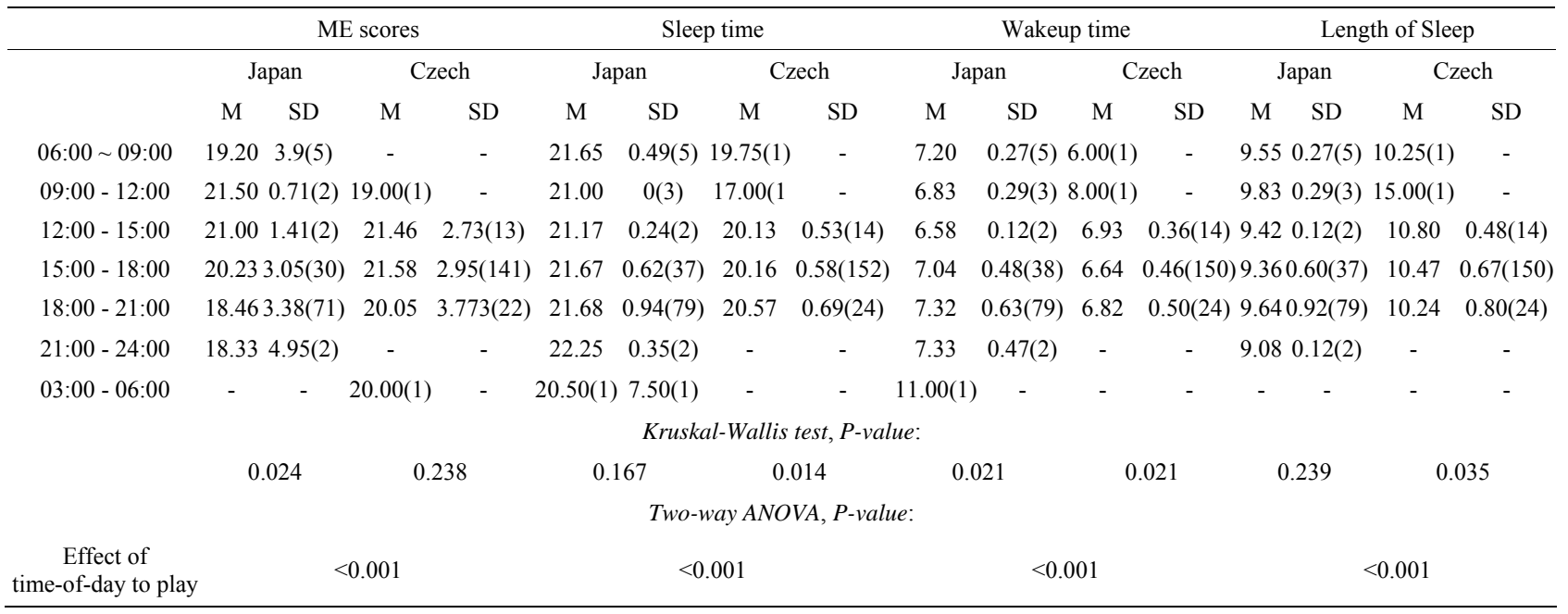




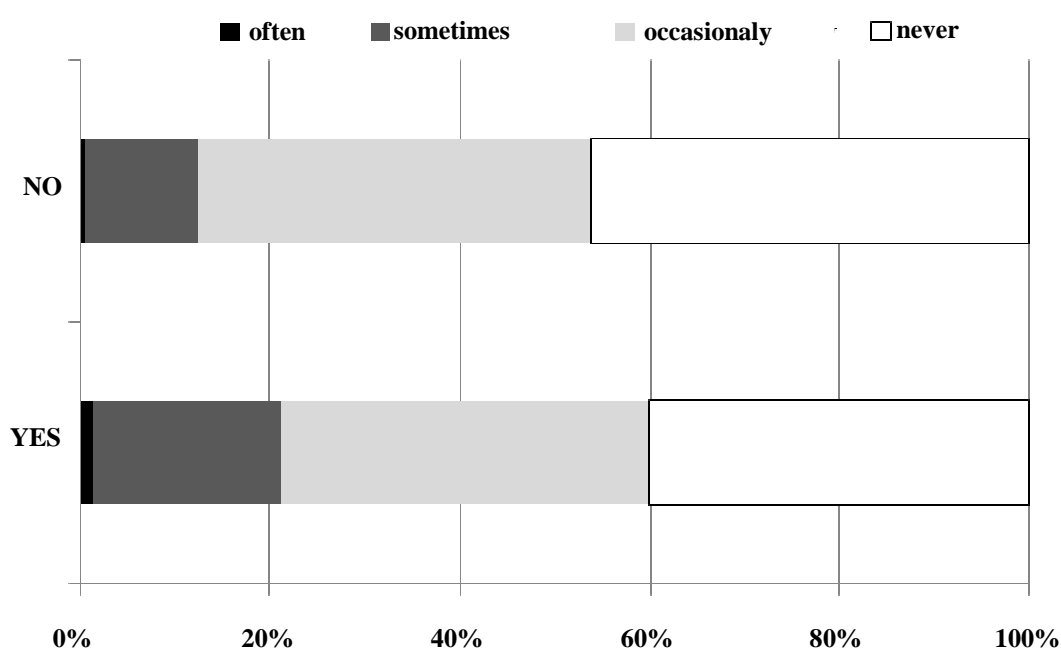

(a)

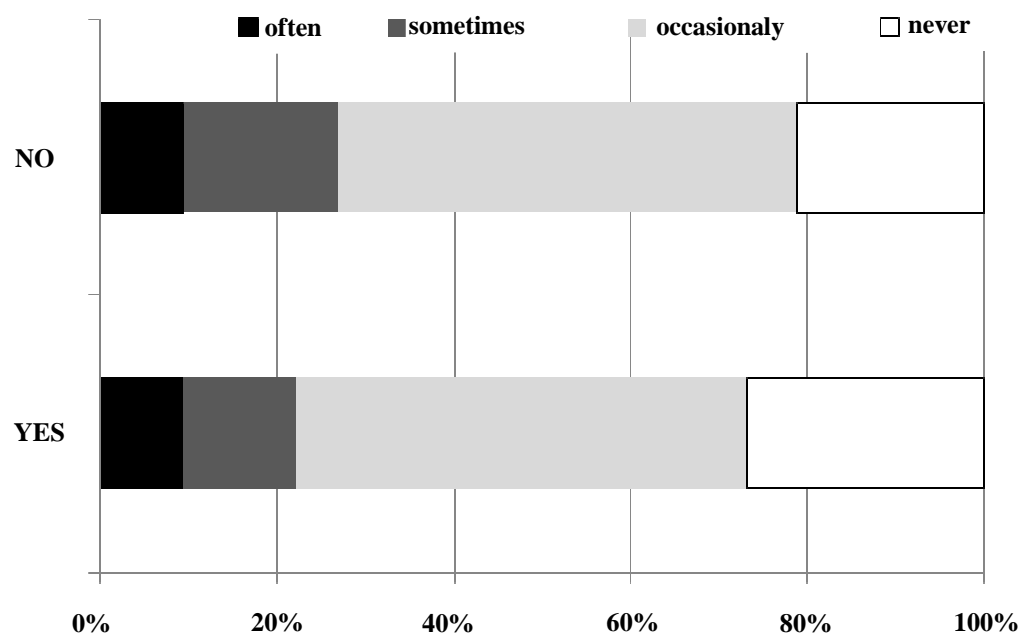

(b)

Figure 1.

Relationship between whether Japanese (a) and Czech (b) infants play the games on display or not and the frequency to be angry.

who cooperated with this survey. This study was performed as an official international research project based on The Official Academic Exchanging Agreement between South Bohemia University and Kochi University.

Thanks would be sincerely and also due to Foundation for several financial supports from Research Promotion by Dean of Faculty of Education, Kochi University (2008-2009), Foundation for the Promotion of International Exchanging Programs (2008-2009), Kochi University, Foundation for The Kochi University President's Discretionary Foundation (2009-2011) and JSPS Foundation to T. Harada (Project No. 22370089: 2010-2013). Thanks are also due to Mis Laura Sato for her careful and kind linguistic-editorial work on this paper before the submission.

\section{References}

BaHammam, A., BinSaeed, A., Al-Faris, E., \& Shaikh, S. (2006). Sleep duration and its correlates in a sample of Saudi elementary school children. Singapore Medicine Journal, 47, 875-881.

Chelminski, I., Ferraro, F. R., Petros, T., \& Plaud, J. J. (1999). An analysis of the evening-morningness imension in "depressive" college students. Journal of Affective Disorders, 52, 19-29. doi:10.1016/S0165-0327(98)00051-2

Drennan, M. D., Klauber, M. R., Kripke, D. F., \& Goyette, L. M. (1991). The effects of depression on the Horne-Ostberg morningness-eveningness score. Journal of Affective Disorders, 23, 93-98. doi:10.1016/0165-0327(91)90096-B

Dworak, M., DiplSportwiss, S. T., Bruns, T., \& Strüder. H. K. (2007) Impact of singular excessive computer game and television exposure on sleep patterns and memory performance of school-aged children. Pediatrics, 120, 978-985. doi:10.1542/peds.2007-0476

Gaina, A., Sekine, M., Hamanishi, S., Chen, X., Kanayama, H., Yamagami, T., Williams, W. R., Heins, E., Seitz, C., Schüz, J., Toschke, A. M., Harth, K., Letzel, S., \& Böhler, E. (2007). Bedtime, television and computer habits of primary school children in Germany. Gesundleitswesen, 69, 151-157.

Giannotti, F., \& Cortesi, F. (2002). Sleep patterns and daytime functions in adolescence. An epidemiological survey of Italian highschool student population. In M. A. Carskadon (Ed.), Adolescents sleep patterns: Biological, social and psychological influences (pp. 132-147). New York: Cambridge University Press.

Harada, T. (2004). Effects of evening light conditions on salivary melatonin of Japanese junior high school students. Journal of Circadian Rhythms, 2, 1-5. doi:10.1186/1740-3391-2-4 
Harada, T. (2008). Diurnal rhythms and sleep habits of Japanese children and students aged $0-25$ yrs - Focusing on environmental factors including those related to $24 \mathrm{~h}$ commercial society. Journal of Chronobiology, 14, 35-43.

Harada, T., \& Takeuchi, H. (2001). Epidemiological study on diurnal rhythms and sleep habits of Japanese children and students aged 6 25 yrs. Journal of Chronobiology, 7, 36-46.

Harada, T., Tanoue, A., \& Takeuchi, H. (2006). Epidemiological studies on dreams, sleep habits and mental symptoms in students aged 18 - 25 years and the 24 hours a day commercialization of Japanese society. Sleep and Biological Rhythms, 4, 274-281. doi:10.1111/j.1479-8425.2006.00232.x

Harada, T., Hirotani, A., Maeda, M., Nomura, H., \& Takeuchi, H. (2007). Correlation between breakfast tryptophan content and morningness-eveningness in Japanese infants and students aged 0 - 15 yrs. Journal of Physiological Anthropology, 26, 201-207. doi:10.2114/jpa2.26.201

Harada, T., Inoue, M., Takeuchi, H., Watanabe, N., Hamada, M., Kadota, G., \& Yamashita, Y. (1998). Study on diurnal rhythms in the life of Japanese University, junior high and elementary school students including morningness-eveningness preference. Bulletin of Faculty of Education, Kochi University Series 1, 56, 1-91. doi:10.3928/00904481-20080701-07

Herman, J. (2008). Circadian rhythm disorders in pediatrics. Pediatric Annals, 37, 488-496. doi:10.1111/j.1365-2869.2005.00463.x

Higuchi, S., Motohashi, Y., Liu, Y., \& Maeda, A. (2005). Effects of playing a computer game using a bright display on presleep physiological variables, sleep latency, slow wave sleep and REM sleep. Journal of Sleep Research, 14, 267-273. doi:10.1080/07420520701657730

Hirata, F. C., Oliveira-Lima, M. C., Sales-de-Bruin, V. M., Nobrega, P. R., Wenceslau, G. P., \& Carvalhedo-de-Bruin, P. F. (2007). Depression in medical school: the influence of morningness-eveningness. Chronobiology International, 24, 939-946.

Honma, K., \& Honma, S. (1998). A human phase-response curve for bright light pulses. Japanese Journal of Psychiatry and Neurology, 42, 167-168.

Japan Parents and Teachers Association (2007). Association research reports on the consciousness of Japanese children and media. Tokyo: Japan Parents and Teachers Association, 1-168.

Kagamimori, S. (2006). Epidemiological aspects of self-reported sleep onset latency in Japanese junior high school children. Journal of Sleep Research, 15, 266-275. doi:10.1111/i.1365-2869.2006.00530.x

Mori, A. (2002). Electric game hazard on human brains. Tokyo: The Publication Department, The Japan Broadcasting Corporation, 1-200.

Portaluppi, F., Smolensky, M. H., \& Touitou, Y. (2010). Effects and methods for biological rhythm research on animals and human beings. Chronobiology International, 27, 1911-1929.

Punamaki, R.-L., Wallenius, M., Nygård, C.-H., Saarni, L., \& Rimpela, A. (2007). Use of information and communication technology (ICT) and perceived health in adolescence: The role of sleeping habits and waking-time tiredness. Journal of Adolescence, 30, 569-585. doi: $10.3109 / 07420528.2010 .516381$
Randler, C. (2008). Morningness-Eveningness comparison in adolescents from different countries around the world. Chronobiology International, 25, 1017-1028. doi:10.1016/j.adolescence.2006.07.004

Smyth, J. M. (2007). Beyond self-selection in video game play: An experimental examination of the consequences of massively multiplayer online role-playing game play. Cyberpsychology and Behavior, 10, 717-721. doi:10.1080/07420520802551519

Takeuchi, H., Morisane, H., Iwanaga, A., Hino, N., Matsuoka, A., \& Harada, T. (2002). Effect of daytime light conditions on sleep habits and morningness-eveningness preference of Japanese students aged 12 - 15 years. Psychiatry and Clinical Neurosciences, 56, 225-226. doi: $10.1089 / \mathrm{cpb} .2007 .9963$

Tazawa, Y., \& Okada, K. (2001). Physical signs associated with excessive television-game playing and sleep deprivation. Pediatrics International, 43, 647-650. doi:10.1046/j.1440-1819.2002.00983.x

Tonetti, L., Fabbri, M., \& Natale, V. (2008). Sex difference in sleeptime preference and sleep need: a cross-sectional survey among Italian pre-adolescents, adolescents, and adults. Chronobiology International, 25, 745-759. doi:10.1046/j.1442-200X.2001.01466.x

Torsvall, M. D., \& Åkerstedt, T. A. (1980). Diurnal type scale construction, consistency and variation in shift work. Scand Journal of Work Environment and Health, 6, 283-290. doi:10.1080/07420520802394191

Van Den Bulck, J. (2004). Television viewing, computer game playing, and internet use and self-reported time to bed and time out of bed in secondary-school children. Sleep, 27, 101-104.

Wada, K., Krejci, M., Ohira, Y., Nakade, M., Takeuchi, H., \& Harada, T. (2009). Comparative study on circadian typology and sleep habits of Japanese and Czech infants aged $0-8$ years. Sleep and Biological Rhythms, 7, 218-221. doi:10.1111/i.1479-8425.2009.00397.x

Waldhauser, F., Weiszenbacher, G., Tatzer, E., Gisinger, B., Waldhauser, M., Schemper, M., \& Frisch, H. (1988). Alterations in nocturnal serum melatonin levels in humans with growth and aging. Journal of Clinical Endocrinology and Metabolism, 66, 648-652, doi: $10.1210 /$ jcem-66-3-648

Wei, R. (2007). Effects of playing violent videogames on Chinese adolescents' pro-violence attitudes, attitudes toward others, and aggressive behavior. Cyberpsychology and Behavior, 10, 371-381. doi:10.1089/cpb.2006.9942

Wiater, A., Lehmkuhl, G., Mitschke, A., \& Fricke-Oerkermann, L. (2008). Sleep, behavior and school performance in children. Padiatrische Praxis, 71, 397-408.

Yokomaku, A., Misao, K., Omoto, F., Yamagishi, R., Tanaka, K., Takada, K., \& Kohyama, J. (2008) A study of the association between sleep habits and problematic behaviors in preschool children. Chronobiology International, 25, 549-564. doi:10.1080/07420520802261705

Zhdanova, I. V., Wurtman, R. J., Lynch, H. J., Ives, J. R., Dollina, A. B., Morabito, C., Matheson, J. K., \& Schomen, D. L. (1995). Pharmaco-dynamics and drug action; sleep-induced effects of low doses of melatonin ingested in the evening. Clinical Pharmacology and Therapy, 57, 552-558. doi:10.1016/0009-9236(95)90040-3 